\title{
Regional differences in the temporal evolution of stroke: a population-based study of Brazil according to sex in individuals aged 15-49 years between 1997 and 2012
}

\author{
Laércio da Silva Paiva ${ }^{1 *}$, Jean Henri Maselli Schoueri ${ }^{1}$, Luiz Vinicius de Alcantara Sousa ${ }^{1}$, \\ Rodrigo Daminello Raimundo ${ }^{2}$, Erika da Silva Maciel ${ }^{3}$, João Antonio Correa ${ }^{4}$ and Fernando Adami ${ }^{1}$
}

\begin{abstract}
Objective: The present study analyzed the temporal trend of stroke mortality according to sex in individuals aged 15-49 years in the different regions of Brazil between 1997 and 2012.

Results: There was progressive reduction in mortality rate due to stroke in Brazil. The reduction trend was the same for both sexes, although mortality remained slightly higher among men. There was a difference in mortality rates according to the administrative region of the country.
\end{abstract}

Keywords: Stroke, Brazil, Epidemiology, Mortality, Temporal trend

\section{Introduction}

Stroke is among the second and third leading causes of death worldwide [1]. It is estimated that across a year, 15 million people experience stroke and about one-third of remains impaired [2]. In Brazil, the proportion is the same: death following stroke only follows deaths due to acute myocardial infarction (AMI) and pneumonia [3].

Among young people, stroke is less common [4], however, in recent years the incidence and risk factors have increased in this population [5]. It has been noted that the increase in the incidence of stroke is higher in women under 30 years of age than in men under 30 years of age [4]. There is a divergence in the literature regarding the magnitude of stroke mortality between the sexes [6-9], although data from the Institute for Health Metrics and Evaluation (2016) show that the overall mortality rate from stroke is higher in females [10].

\footnotetext{
*Correspondence: laercio.paiva@fmabc.br

${ }^{1}$ Departamento de Saúde da Coletividade, Laboratório de Epidemiologia e Análise de dados, Faculdade de Medicina do ABC, Av. Lauro Gomes, 2000, Vila Sacadura Cabral, Santo André, SP CEP: 09060-870, Brazil Full list of author information is available at the end of the article
}

In addition, studies have related the risk of stroke with other factors, for example socioeconomic conditions, and have demonstrated the frequency of occurrence and consequences of stroke in different administrative regions of Brazil $[11,12]$. It should be emphasized that the consequences of stroke in young adults are catastrophic due to the limitations it causes in the period of high productivity [1].

The question arises as to the applicability of the international findings to the Brazilian context. Thus, the present study aims to describe the temporal trend of mortality due to stroke in individuals aged 15-49 years, stratified by sex in the different regions of Brazil between 1997 and 2012.

\section{Main text \\ Methods}

This was an ecological study in Brazil, which evaluated the temporal trend of stroke mortality in young Brazilian adults aged 15-49 years, from 1997 to 2012, taking into account the sex of individuals and the region of the country, by means of a secondary analysis of data. Data were collected from the Department of Informatics of 
the Unified Health System (DATASUS), an agency of the Ministry of Health that includes a national database and is considered an important management tool in Brazilian healthcare [13].

The study considered all deaths recorded by the Mortality Information System (SIM) for stroke in men and women aged 15-49 years and took regions of Brazil into account. The period studied was January 1, 1997 to December 31, 2012. Data from the SIM were used and was publicly available and unrestricted by the DATASUS website (http://www.datasus.gov.br). According to the most recent report, data coverage has been improving across the last decade, reaching $96.1 \%$ in Brazil in 2011 [14].

Stroke was defined according to the tenth revision of the International Classification of Diseases (ICD10) codes: I60 (subarachnoid hemorrhage), I61 (intracranial hemorrhage), I63 (cerebral infarction) and I64 (stroke not specified between ischemic or hemorrhagic) [15].

All DATASUS data selection was performed by two independent researchers using extraction sheets designed by the authors; a third researcher was responsible for correcting any discrepancies found. The mortality calculation was performed by dividing the number of deaths by stroke in young adults, stratified by sex and administrative region of Brazil, by the total population at risk and then multiplied by 100,000.

Stroke mortality was standardized by age using the direct method, with the World Health Organization (WHO) standard population as the reference population [16].

The percentage change (PC) and the annual percentage change (APC) are the two trend measures in this analysis. For the calculation of the PC, the initial amount of the same rate was subtracted from the final value of the adjusted rate for stroke mortality, dividing the result by the initial value of the rate and multiplied by 100 . The calculation was repeated for each region and according to sex. The APC, on the other hand, was calculated using the angular coefficient $(\beta)$, derived from the linear regression as shown by Fay et al. [17].

The data used in this project come from a public database of national scope, which is unrestricted and allows public access. This means that there is no need for evaluation by the Research Ethics Committee according to the Resolution of the National Health Council (CNS) of no 466 of December 12, 2012.

\section{Statistical analysis}

To describe the mortality rate of stroke, the relative and absolute frequencies were used. Linear regression was applied to compare temporal trends, with calendar years as the independent variable, and mortality as the dependent variable. We estimated the slope $(\beta)$, its respective probability (p), and predictive capacity of the model $\left(\mathrm{r}^{2}\right)$. The level of significance was set at $5 \%$. The statistical program used was Stata, version 11.0.

\section{Results}

In Brazil, between 1997 and 2012, there were 62,751 deaths in men and 62,115 deaths in women between the ages of 15 and 49 (Table 1 ).

In Table 1 it can be observed that the Annual Percentage Change (APC) of the age-standardized mortality rate is negative throughout the country, with the predominance of reductions in the South, $\mathrm{APC}=-0.056$ (CI 95\% - 0.064; 0.049) for men and -0.059 (CI $95 \%-0.066$; -0.052$)$ for women; and in the Southeast region, $\mathrm{APC}=-0.061(\mathrm{CI} 95 \%-0.066 ;-0.055)$ for the male population and -0.054 (CI $95 \%-0.059 ; 0.050)$ for the female population.

In addition, there was a progressive decrease in the mortality rate due to age-standardized stroke in Brazil. There is similarity for both sexes, but mortality is slightly higher among men (Fig. 1).

Table 1 Deaths, PC and APC of stroke in men and women aged 15-49 between 1997 and 2012

\begin{tabular}{|c|c|c|c|c|c|c|}
\hline \multirow{2}{*}{$\begin{array}{l}\text { Characteristics } \\
\text { Regions }\end{array}$} & \multicolumn{3}{|l|}{ Men } & \multicolumn{3}{|l|}{ Women } \\
\hline & Deaths & PC & APC $(95 \% \mathrm{Cl})$ & Deaths & PC & APC $(95 \% \mathrm{Cl})$ \\
\hline North & 3663 & -19.73 & $-0.019(-0.029 ;-0.008)^{*}$ & 3520 & -27.59 & $-0.025(-0.034 ;-0.016)^{*}$ \\
\hline Northeast & 14,025 & -20.00 & $-0.022(-0.029 ;-0.015)^{*}$ & 14,763 & -35.16 & $-0.027(-0.035 ;-0.020)^{*}$ \\
\hline Southeast & 32,128 & -58.54 & $-0.061(-0.066 ;-0.055)^{*}$ & 30,931 & -54.74 & $-0.054(-0.059 ;-0.050)^{*}$ \\
\hline South & 8624 & -58.33 & $-0.056(-0.064 ;-0.049)^{*}$ & 8609 & -57.14 & $-0.059(-0.066 ;-0.052)^{*}$ \\
\hline Midwest & 4311 & -57.77 & $-0.053(-0.060 ;-0.045)^{*}$ & 4292 & -53.78 & $-0.057(-0.064 ;-0.049)^{*}$ \\
\hline Brazil & 62,751 & -50.38 & $-0.049(-0.054 ;-0.044)^{*}$ & 62,115 & -49.57 & $-0.048(-0.513 ;-0.446)^{*}$ \\
\hline
\end{tabular}

$P C$ percent change, $A P C$ annual percent change, 95\% Cl 95\% Confidence Interval

* Statistically significant difference 

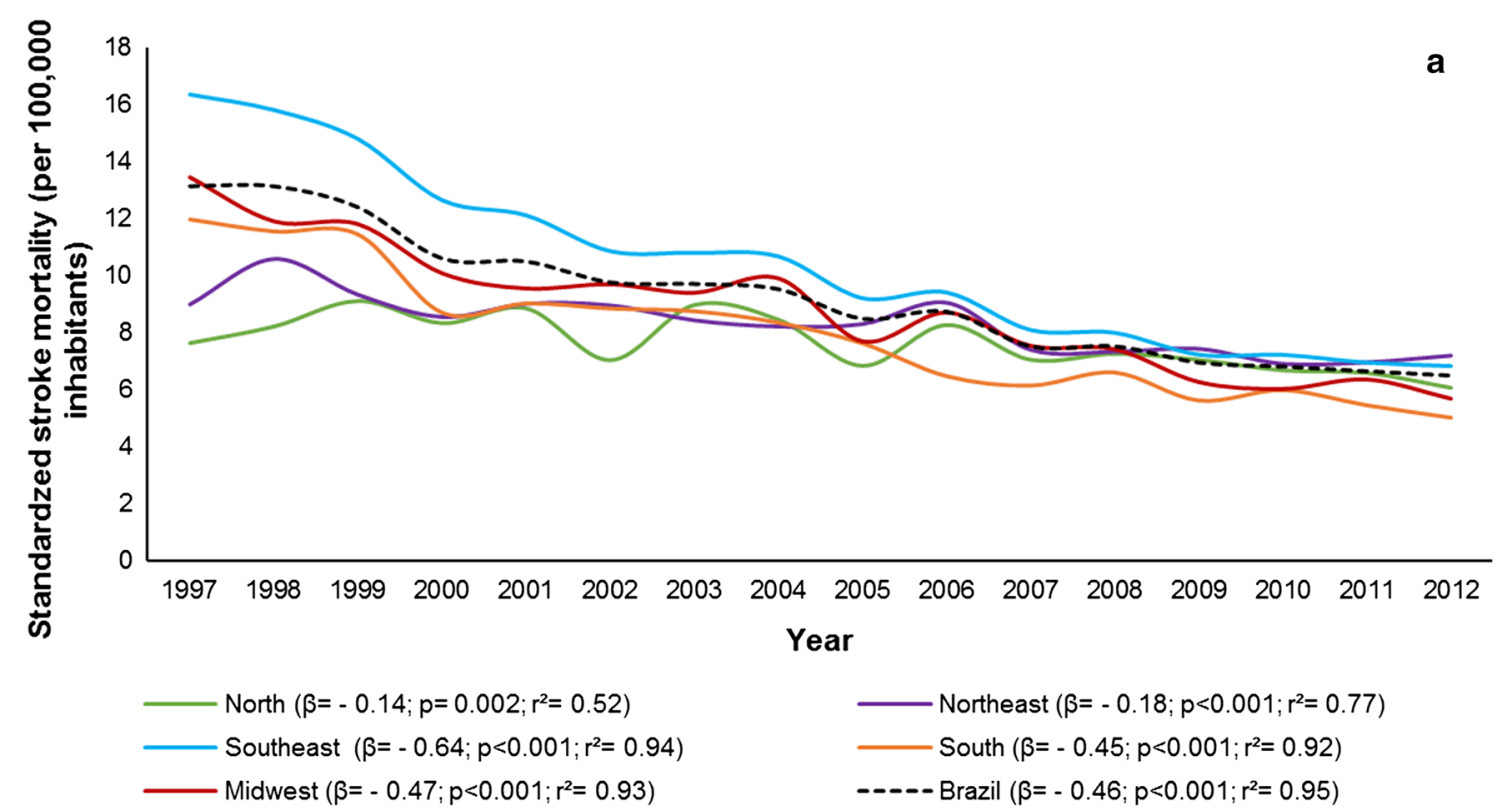

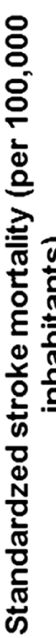

Midwest $\left(\beta=-0.47 ; p<0.001 ; r^{2}=0.93\right)$

b

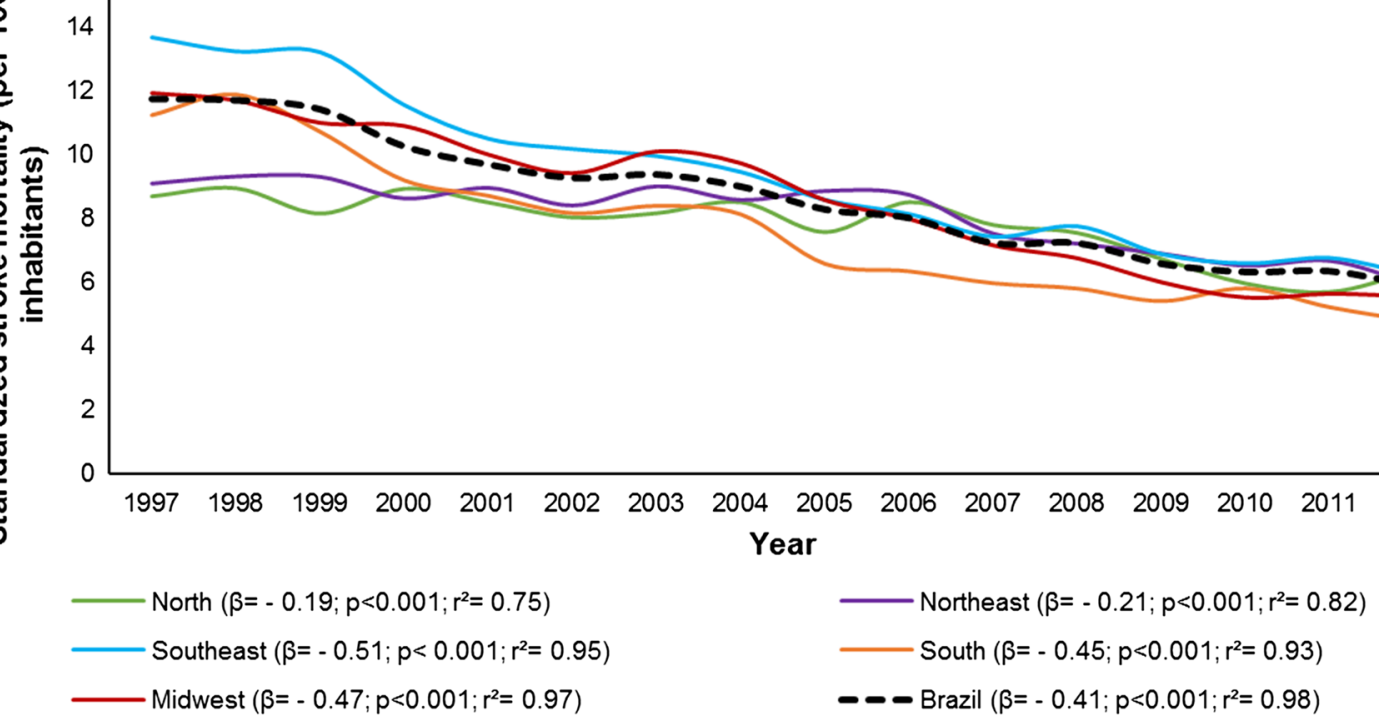

Fig. 1 Age-standardized mortality rate for stroke (100,000 inhabitants) among men (a) and women (b), resident in Brazil aged 15-49 years, in the period from 1997 to 2012 and estimates obtained from linear regression, according to year and regions

There was a difference in mortality rates according to the country's administrative region. The Southeast region presented the largest reduction in deaths due to stroke in men $\left(\beta=-0.64 ; \mathrm{p}<0.001 ; \mathrm{r}^{2}=0.94\right)$ and for women $\left(\beta=-0.51, p<0.001 ; r^{2}=0.95\right)$; and the North region presented the lowest risk reduction for stroke in men $\left(\beta=-0.14 ; \mathrm{p}=0.002 ; \mathrm{r}^{2}=0.52\right)$ and women $(\beta=-0.19$; $\mathrm{p}<0.001 ; \mathrm{r}^{2}=0.75$ ) (Fig. 1 and Additional file 1 ).

When stratifying by regions of Brazil and age groups, between 1997 and 2012, there is a significant reduction in the mortality rate due to stroke in the Northern region in the age range $30-39$ and $40-49$ years in men and in the age groups of 20-29 and 40-49 years in women. In the Northeastern and Southern regions, the reduction in mortality due to stroke occurs in the age range between 20 and 49 years for both sexes. In the Southeast and Central-West regions, this decrease occurs in all age groups, both for men and women, except for the men of 15-19 years of the Midwest (Table 2). 
Table 2 Linear regression of mortalityt* by stroke (per 100,000 inhabitants) of Brazilians aged 15-49 years, between 1997 and 2012, according to the regions of Brazil stratified by sex Source: Mortality Information System (SIM) obtained by the Information Department of the Brazilian National Health System (DATASUS)

\begin{tabular}{|c|c|c|c|c|}
\hline \multirow[t]{3}{*}{ Country regions } & \multicolumn{4}{|l|}{ Linear regression mortality } \\
\hline & \multicolumn{2}{|l|}{ Men } & \multicolumn{2}{|l|}{ Women } \\
\hline & $\beta(95 \% \mathrm{Cl})$ & p & $\beta(95 \% \mathrm{Cl})$ & $p$ \\
\hline \multicolumn{5}{|l|}{ Age group (years) } \\
\hline \multicolumn{5}{|l|}{ North } \\
\hline $15-19$ & $-0.004(-0.020 ; 0.042)$ & 0.841 & $-0.013(-0.045 ; 0.019)$ & 0.402 \\
\hline $20-29$ & $-0.002(-0.068 ; 0.063)$ & 0.945 & $-0.034(-0.063 ;-0.005)$ & 0.024 \\
\hline $30-39$ & $-0.110(-0.167 ;-0.052)$ & 0.001 & $-0.072(-0.157 ; 0.012)$ & 0.090 \\
\hline $40-49$ & $-0.399(-0.685 ;-0.113)$ & 0.010 & $-0.635(-0.843 ;-0.427)$ & $<0.001$ \\
\hline \multicolumn{5}{|l|}{ Northeast } \\
\hline $15-19$ & $0.009(-0.020 ; 0.039)$ & 0.500 & $-0.010(-0.025 ; 0.003)$ & 0.139 \\
\hline $20-29$ & $-0.047(-0.093 ;-0.001)$ & 0.045 & $-0.054(-0.084 ;-0.024)$ & 0.002 \\
\hline $30-39$ & $-0.149(-0.207 ;-0.092)$ & $<0.001$ & $-0.228(-0.269 ;-0.188)$ & $<0.001$ \\
\hline $40-49$ & $-0.497(-0.685 ;-0.309)$ & $<0.001$ & $-0.522(-0.755 ;-0.289)$ & $<0.001$ \\
\hline \multicolumn{5}{|l|}{ Southeast } \\
\hline $15-19$ & $-0.040(-0.068 ;-0.012)$ & 0.008 & $-0.045(-0.069 ;-0.021)$ & 0.001 \\
\hline $20-29$ & $-0.058(-0.094 ;-0.022)$ & 0.004 & $-0.093(-0.131 ;-0.056)$ & $<0.001$ \\
\hline $30-39$ & $-0.478(-0.574 ;-0.383)$ & $<0.001$ & $-0.475(-0.556 ;-0.394)$ & $<0.001$ \\
\hline $40-49$ & $-1.889(-2.138 ;-1.640)$ & $<0.001$ & $-1.360(-1.501 ;-1.218)$ & $<0.001$ \\
\hline \multicolumn{5}{|l|}{ South } \\
\hline $15-19$ & $-0.010(-0.044 ; 0.024)$ & 0.528 & $0.005(-0.019 ; 0.029)$ & 0.670 \\
\hline $20-29$ & $-0.034(-0.069 ;-0.001)$ & 0.047 & $-0.080(-0.121 ;-0.040)$ & 0.001 \\
\hline $30-39$ & $-0.310(-0.387 ;-0.233)$ & $<0.001$ & $-0.339(-0.422 ;-0.256)$ & $<0.001$ \\
\hline $40-49$ & $-1.365(-1.571 ;-1.159)$ & $<0.001$ & $-1.333(-1.549 ;-1.116)$ & $<0.001$ \\
\hline \multicolumn{5}{|l|}{ Central-West } \\
\hline $15-19$ & $-0.008(-0.047 ; 0.031)$ & 0.666 & $-0.047(-0.082 ;-0.012)$ & 0.012 \\
\hline $20-29$ & $-0.062(-0.099 ;-0.025)$ & 0.003 & $-0.098(-0.144 ;-0.052$ & $<0.001$ \\
\hline $30-39$ & $-0.377(-0.508 ;-0.247)$ & $<0.001$ & $-0.378(-0.456 ;-0.301)$ & $<0.001$ \\
\hline $40-49$ & $-1.302(-1.539 ;-1.065)$ & $<0.001$ & $-1.280(-1.504 ;-1.055)$ & $<0.001$ \\
\hline
\end{tabular}

$\beta$ regression slope, 95\% Cl 95\% confidence interval

†Crude rate. ${ }^{*}$ International Statistical Classification of Diseases and Related Health Problems, 10th revision: 160, 161, 163 to 164 [15]

\section{Discussion}

Cerebrovascular diseases are the leading cause of mortality in women and the second in men in industrialized countries [18]. In this context, stroke should be highlighted as, besides being an important cause of functional impairment, it is expected that associated mortality rates will increase, reaching 7.8 million deaths by 2030 [19-21].

However, the situation is different for young adults, in an American study based on secondary data, a decrease in mortality due to stroke was observed in young adults suggesting that there was improvement in the recognition and treatment of the disease in the last two decades [22].

Global data [10] indicate a reduction in the mortality rate due to stroke in young adults, in men 14.01 (95\%
CI $13.17 ; 15.30)$ in 1990 to 12.57 (95\% CI $12.07 ; 13.06)$ in 2016 and in women 10.83 (95\% CI 10.14; 11.67) in 1990 to 7.44 (95\% CI 7.13; 7.75) in 2016.

Similarly, in a national study, a reduction in global stroke mortality in Brazil became evident [12, 23] among young adults, which is in agreement with our results. Both results indicate that this reduction has been occurring for years in both sexes.

The results from this study regarding may be justified, in part, by greater care in modifying and treating vascular risk factors, especially regarding modifiable risk factors such as hypertension, diabetes, dyslipidemia, a sedentary lifestyle, and smoking [24]. In addition, one cannot forget that men and women have different physiologies. In this context, the guidelines already show 
the importance of risk factors for stroke that are more commonly-or exclusively-found in the female population, such as migraine with aura, depression, diabetes mellitus, and a history of complications in pregnancy [25].

Additionally, it is necessary to consider a possible association between socioeconomic status and the risk for stroke. In a national study, it was concluded that income inequity should be considered as a determinant health factor in less well-off patients [26]. The same study also indicated that the participation of each state in the financing of the health system has a negative impact on stroke mortality in the poorest regions of the North and Northeast of Brazil over time; at the same time, the highest expenditure of states regarding health was related to increased stroke mortality [26].

Brazil is divided into five regions, North, Northeast, Southeast, South and Midwest. The Southeast region has the largest number of inhabitants and the North region the smallest of the country [27].

It should be taken into account that the populations of the North and Northeast of Brazil present a lower rate of urbanization concomitant with higher rates of child dependence and mortality, among other socioeconomic indicators that can be interpreted as markers of development of a region. Comparatively, the Southeast region, as well as the South region, have the highest monthly family incomes per capita in Brazil, which may explain why the least developed regions (North and Northeast) present lower reductions in the mortality rate due to stroke in young adults [28].

After all, given that higher incidence and mortality rates can be seen in low-and middle-income countries when compared to high-income countries, we could extrapolate to regions of the same country that present different levels of development in order to understand the results found [29].

Thus, along with the above mentioned reasons and, similar to what occurs with several other diseases with serious consequences for the population, the prevention of stroke is paramount. After all, if prevention is done correctly, it avoids both the event and its direct or indirect complications that may be related to slower recovery and worse functional results, along with affecting mortality rates $[30,31]$.

In this context, the control of risk factors is essential for the prevention of stroke [32], especially as some modifiable risk factors account for about $90 \%$ of the risks attributed to the stroke population [33]. Moreover, there are high hospital costs related to stroke, especially in the first year after stroke [34].

Thus, it is necessary to carry out new studies to understand the temporal trends of the risk factors for stroke in these regions of Brazil that over time may change the scenario of this young adult population.

\section{Conclusion}

Stroke mortality has declined in Brazil in all regions of the country for both young men and women; the reduction is slightly higher among men. The Southeast region showed the highest declines and the North region showed the lowest, in both sexes.

\section{Limitations}

The present study is a secondary data analysis and therefore there is a difference between the amount of cases and their respective registration, apart from an inequality between the number of cases registered by region. More than conjecture, this is supported by the uncertainty of the data presented in some states of the North and Northeast regions. This would restrict the usefulness of their data, especially as a result of the inconsistencies in comparison with data from states and capital municipalities [35] or in comparison with the data coverage of the other Brazilian regions [14].

In addition, stratification by Stroke subtype was not possible, as approximately one-third of the deaths recorded in DATASUS refer to the "not specified" (NE) category, in other words indicating either ischemic or hemorrhagic stroke.

\section{Additional file}

Additional file 1. Standardized mortality estimated for standardized stroke (per 100,000 population) between men and women, residing in Brazil aged 15 to 49 years, from 1997 to 2012 and estimates obtained from linear regression, second year and regions.

\section{Abbreviations}

AMI: acute myocardial infarction; DATASUS: Department of Informatics of the Unified Health System; SIM: Mortality Information System; ICD10: International Classification of Diseases; WHO: World Health Organization; PC: percentage change; APC: annual percentage change; Cl 95\%: 95\% confidence interval.

\section{Authors' contributions}

LSP, JHMS and FA participated in the design of the study. LSP, LVAS and JHMS participated in the statistical analysis. LSP, JHMS, LVAS, RDR, ESM, JAC and FA contributed to writing and revising the manuscript. All authors read and approved the final manuscripts.

\section{Author details}

${ }^{1}$ Departamento de Saúde da Coletividade, Laboratório de Epidemiologia e Análise de dados, Faculdade de Medicina do ABC, Av. Lauro Gomes, 2000, Vila Sacadura Cabral, Santo André, SP CEP: 09060-870, Brazil. ${ }^{2}$ Departamento de Saúde da Coletividade, Laboratório de Delineamento de Estudos e Escrita Científica, Faculdade de Medicina do ABC, Av. Lauro Gomes, 2000, Vila Sacadura Cabral, Santo André, SP CEP: 09060-870, Brazil. ${ }^{3}$ Universidade Federal do Tocantis, Avenida Lourdes Solino s/nº-Setor Universitário, Miracema, TO, Brazil. ${ }^{4}$ Disciplina de Angiologia e Cirurgia Vascular, Faculdade de Medicina do ABC, Av. Lauro Gomes, 2000, Vila Sacadura Cabral, Santo André, SP CEP: 09060-870, Brazil. 


\section{Acknowledgements \\ Not applicable.}

\section{Competing interests}

The authors declare that they have no competing interests.

\section{Availability of data and materials}

All relevant search data is in the article.

\section{Consent to publish}

Not applicable.

\section{Funding}

This study was supported by the National Council for Scientific and Technological Development CNPq (number: 143234/2016-1).

\section{Ethics approval and consent to participate}

Not applicable.

\section{Publisher's Note}

Springer Nature remains neutral with regard to jurisdictional claims in published maps and institutional affiliations.

\section{Received: 9 March 2018 Accepted: 11 May 2018}

Published online: 21 May 2018

\section{References}

1. Smajlovic D. Strokes in young adults: epidemiology and prevention. Vasc Health Risk Manag. 2015;11:157-64.

2. Stoller $\mathrm{O}$, de Bruin ED, Knols $\mathrm{RH}$, Hunt KJ. Effects of cardiovascular exercise early after stroke: systematic review and meta-analysis. BMC Neurol. 2012;12:45

3. Portal da Saúde. Disponível em: http://portalsaude.saude.gov.br/index .php/cidadao/principal/agencia-saude/19968-juiz-de-fora-ganha-refor co-de-r-3-2-milhoes-para-tratar-avc. Acesso em 24 Apr 2016.

4. Griffiths D, Sturm J. Epidemiology and etiology of young stroke. Stroke Res Treat. 2011;2011:209370.

5. Singhal AB, Biller J, Elkind MS, Fullerton HJ, Jauch EC, Kittner SJ, Levine DA, Levine SR. Recognition and management of stroke in young adults and adolescents. Neurology. 2013:81(12):1089-97.

6. Modan B, Wagener DK. Some epidemiological aspects of stroke: mortality/morbidity trends, age, sex, race, socioeconomic status. Stroke. 1992;23(9):1230-6.

7. Di Carlo A, Lamassa M, Baldereschi M, Pracucci G, Basile AM, Wolfe CD, Giroud M, Rudd A, Ghetti A, Inzitari D. Sex differences in the clinical presentation, resource use, and 3-month outcome of acute stroke in Europe: data from a multicenter multinational hospital-based registry. Stroke. 2003:34(5):1114-9.

8. Holroyd-Leduc JM, Kapral MK, Austin PC, Tu JV. Sex differences and similarities in the management and outcome of stroke patients. Stroke. 2000;31(8):1833-7.

9. Ayala C, Croft JB, Greenlund KJ, Keenan NL, Donehoo RS, Malarcher AM, Mensah GA. Sex differences in US mortality rates for stroke and stroke subtypes by race/ethnicity and age, 1995-1998. Stroke. 2002;33(5):1197-201.

10. Institute for Health Metrics and Evaluation (IHME). GBD Compare. Seattle, WA: IHME, University of Washington, 2015. http://vizhub.healthdata.org/ gbd-compare. Accessed 10 June 2016

11. Glymour MM, Avendano M, Haas S, Berkman LF. Lifecourse social conditions and racial disparities in incidence of first stroke. Ann Epidemiol. 2008;18(12):904-12

12. Adami F, Figueiredo FW, Paiva Lda S, Sa TH, Santos EF, Martins BL, Valenti VE, Abreu LC. Mortality and incidence of hospital admissions for stroke among Brazilians aged 15 to 49 years between 2008 and 2012. PLoS ONE. 2016;11(6):e0152739.

13. Portal da Saúde. Disponível em: http://portalsaude.saude.gov.br/index .php/o-ministerio/principal/secretarias/svs/mortalidade. Acesso em 22 Apr 17.
14. Coordenação Geral de Informações e Análise Epidemiológica-CGIAE. Disponível em: http://tabnet.datasus.gov.br/cgi/sim/Consolida_ Sim_2011.pdf. Acesso em: 22 Apr 17.

15. Organização Mundial da Saúde. Disponível em: http://www.who.int/class ifications/icd/en/. Acesso em: 28 May 16.

16. Ahmad OB, Boschi-Pinto C, Lopez AD, Murray CJL, Lozano R, Inoue M. Age standardization of rates: a new who standard. GPE Discussion Paper Series: No.31. EIP/GPE/EBD World Health Organization 2001.

17. Fay MP, Tiwari RC, Feuer EJ, Zou Z. Estimating average annual percent change for disease rates without assuming constant change. Biometrics. 2006;62(3):847-54

18. Arboix A. Cardiovascular risk factors for acute stroke: Risk profiles in the different subtypes of ischemic stroke. World J Clin Cases. 2015:3(5):418-29.

19. Meschia JF, Bushnell C, Boden-Albala B, Braun LT, Bravata DM, Chaturvedi S, Creager MA, Eckel RH, Elkind MS, Fornage M, et al. Guidelines for the primary prevention of stroke: a statement for healthcare professionals from the American Heart Association/American Stroke Association. Stroke. 2014;45(12):3754-832.

20. Luengo-Fernandez R, Paul NL, Gray AM, Pendlebury ST, Bull LM, Welch SJ, Cuthbertson FC, Rothwell PM. Population-based study of disability and institutionalization after transient ischemic attack and stroke: 10-year results of the Oxford Vascular Study. Stroke. 2013;44(10):2854-61.

21. Kuklina EV, Tong X, George MG, Bansil P. Epidemiology and prevention of stroke: a worldwide perspective. Expert Rev Neurother. 2012;12(2):199-208.

22. Poisson SN, Glidden D, Johnston SC, Fullerton HJ. Deaths from stroke in US young adults, 1989-2009. Neurology. 2014;83(23):2110-5.

23. Sousa LVA, Paiva LDS, Fiqueiredo F, Almeida T, Oliveira FR, Adami F. Trends in stroke-related mortality in the $A B C$ region, Sao Paulo, Brazil: an ecological study between 1997 and 2012. Open Cardiovasc Med J. 2017:11:111-9.

24. Romero JR, Morris J, Pikula A. Stroke prevention: modifying risk factors. Ther Adv Cardiovasc Dis. 2008;2(4):287-303.

25. The LN. Sex differences and stroke prevention. The Lancet Neurology. 2014;13(4):339

26. Vincens N, Stafstrom M. Income inequality, economic growth and stroke mortality in brazil: Iongitudinal and regional analysis 2002-2009. PLoS ONE. 2015;10(9):e0137332.

27. Instituto de Pesquisa e Economia Aplicada_IPEA. Atlas de desenvolvimento humano no Brasil. http://www.atlasbrasil.org.br/2013/pt/ranking. Accessed 30 Jan 2018.

28. Bivar W, Abrantes FJ, Ramos RLO, Neto WJS, Simões PCM, Ta DW, de Magalhães MS: INSTITUTO BRASILEIRO DE GEOGRAFIA E ESTATÍSTICA-IBGE.

29. Lee H, Nam YS, Lee KM. Development-assistance strategies for stroke in low-and middle-income countries. J Korean Med Sci. 2015;30(Suppl 2):S139-42

30. Kronenberg G, Gertz K, Heinz A, Endres M. Of mice and men: modelling post-stroke depression experimentally. Br J Pharmacol. 2014:171(20):4673-89.

31. Willey JZ, Disla N, Moon YP, Paik MC, Sacco RL, Boden-Albala B, Elkind MS, Wright CB. Early depressed mood after stroke predicts long-term disability: the Northern Manhattan Stroke Study (NOMASS). Stroke. 2010;41(9):1896-900.

32. Aoki J, Uchino K. Treatment of risk factors to prevent stroke. Neurotherapeutics. 2011;8(3):463-74.

33. O'Donnell MJ, Chin SL, Rangarajan S, Xavier D, Liu L, Zhang H, RaoMelacini P, Zhang X, Pais P, Agapay S, et al. Global and regional effects of potentially modifiable risk factors associated with acute stroke in 32 countries (INTERSTROKE): a case-control study. Lancet. 2016:388(10046):761-75.

34. Luengo-Fernandez R, Gray AM, Rothwell PM. A population-based study of hospital care costs during five years after TIA and stroke. Stroke. 2012;43(12):3343-51.

35. Andrade CLTD, Szwarcwald CL. Desigualdades sócio-espaciais da adequação das informações de nascimentos e óbitos do Ministério da Saúde, Brasil, 2000-2002. Cadernos de Saúde Pública. 2007:23:1207-16. 